\title{
Development of patch stack antenna for CP-SAR sensor
}

\author{
Muhammad Fauzan Edy Purnomo ${ }^{1}$, Vita Kusumasari ${ }^{2}$, Rusmi Ambarwati ${ }^{3}$, Sigit Kusmaryanto $^{4}$, \\ Sholeh Hadi Pramono ${ }^{5}$, Dwi Fadila Kurniawan', Akio Kitagawa \\ ${ }^{1,3,4,5,6}$ Electrical Department, Faculty of Engineering, Brawijaya University, Malang, Indonesia \\ ${ }^{2}$ Mathematics Department, Faculty of Mathematics and Natural Sciences, Universitas Negeri Malang, Malang, Indonesia \\ ${ }^{7}$ Electrical Engineering and Computer Science, Kanazawa University, Ishikawa, Japan
}

\begin{tabular}{l} 
Article Info \\
\hline Article history: \\
Received Feb 18, 2020 \\
Revised Apr 30, 2020 \\
Accepted May 20, 2020
\end{tabular}

Keywords:

Basic configuration

CP-SAR

LHCP

Patches stack

Triangular truncated

\begin{abstract}
In this paper, we obtain the basic configuration of the left-hand circular polarization (LHCP) array two patches stack triangular truncated microstrip antenna. This construction use the basic corporate feed microstrip-line with modified lossless $\mathrm{T}$-junction power divider on radiating patch for circularly polarized-synthetic aperture radar (CP-SAR) sensor embedded on airspace with compact, small, and simple configuration. The design of Circular Polarization $(\mathrm{CP})$ is realized by truncating the whole three tips and adjusting the parameters of antenna at the resonant frequency, $f=5.2 \mathrm{GHz}$. The results of characteristic performance and $S$-parameter for the LHCP array two patches stack antenna at the resonant frequency show successively about $7.24 \mathrm{dBic}$ of gain, $1.99 \mathrm{~dB}$ of axial ratio $(A r)$, and $-11.43 \mathrm{~dB}$ of $S$-parameter. Moreover, the impedance bandwidth and the $3 \mathrm{~dB}-\mathrm{Ar}$ bandwidth of this antenna are around $560 \mathrm{MHz}(10.77 \%)$ and $50 \mathrm{MHz}(0.96 \%)$, respectively.
\end{abstract}

This is an open access article under the CC BY-SA license.

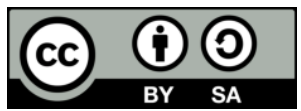

\section{Corresponding Author:}

Muhammad Fauzan Edy Purnomo, Department of Electrical Engineering, Faculty of Engineering, Brawijaya University, MT. Haryono 167, Malang 65145, Indonesia. Email: mfauzanep@ub.ac.id

\section{INTRODUCTION}

One of an active sensor for the remote sensing application in the microwave band is synthetic aperture radar (SAR). An object or phenomenon can be observed by this application without touching it. Also, it helps human being related to the area of observation, such as surveillance, disaster mitigation, mapping, land, air, and ocean. SAR systems can operate at some different bands and polarizations. The most common band-frequency is $C$-band which has an approximately $5 \mathrm{~cm}$ wavelength. It is used on Radarsat and Envisat systems. $S$-band $(\lambda \approx 10 \mathrm{~cm})$ and $L$-band $(\lambda \approx 20 \mathrm{~cm})$ are also common [1]. Because the wavelength is longer, it penetrates surfaces better. Then, it is useful for sea ice, soil moisture, and vegetation applications where the surface penetration is desirable.

Because of the use of circularly polarized-synthetic aperture radar (CP-SAR) sensor, the full characteristic of backscattered SAR signal can pass through the random object. If we compare CP-SAR with the linear polarization (LP) SAR sensor, then a great amount of information about the image target will be occurred $[2,3]$. Each antenna can generate a wave that yields a circular polarization (CP). The technique to achieve $\mathrm{CP}$ can be easily obtained by proper adjusting the element parameters, determining locus feed, and constructing feed. In the triangular microstrip antenna simulation, the performances of significant variation are also influenced by the feeding shape and their position toward the radiating patches [4-6].

This paper presents the development of the left-hand circular polarization (LHCP) array two patches stack triangular truncated microstrip antenna. The study involves the development of the two patches as 
basic construction for CP-SAR sensor. This construction uses the double-stacked substrate with low dielectric constant, modified radiating patch shape using microstrip-line for multi-resonant frequency, and a circle-slotted parasitic patch for CP-SAR sensor embedded on aircraft with compact, small, and simple configuration that fundamentally construct to mold a substantial planar array. This design is modified from previous research about the antenna without patch stack and the use of the proximity feeding [7]. The new antenna design has ability to work in higher frequency and to achieve the wider bandwidth of impedance and axial ratio. The design of power divider network is often limited by the restrictions imposed by radiating patches dimensions. The feeding network is a multi-port power divider circuit which is an important element in the design of corporate feed beam-forming network configuration.

The power is distributed to radiating patches through the multi-port power divider. This is also a microwave device that is useful for phased-array antennas, mixers, and active devices. This modified antenna design is fed by $1: n$ ( $n$ is a number of patches) power divider network involving T-junctions called corporate feeding-line. T-junctions are compensated by adjusting the length of the three microstrip-lines where the length of two or three of them is about $\lambda / 4$ for matching impedance $50 \Omega$ [7-10]. We can control the directed beam by rotate one of the adjacent patches on the opposite direction of $180^{\circ}$ and also add more patches. In this paper, we describe the corporate feeding-line of three ports for two patches of LHCP array antennas that close lossless, reciprocal $(-3 \mathrm{~dB})$ and matched load. The results obtained from the study reveal $S$-parameter, frequency characteristic, input impedance, radiation pattern, and antenna efficiency of this modified antenna.

\section{RESEARCH METHOD}

In this investigation, we conduct and discuss numerical simulation result related to the microstrip antenna. In particular, the analysis focuses on the study of triangular truncated microstrip antenna for LHCP of array $2 \times 1$ patches. In this case, the array antenna uses two patches as a transmitter, $T x$, and a receiver, $R x[4,5]$. Table 1 shows the specification for the $C$-Band CP-SAR of aircraft antenna [6]. The Method of Moments (MoM) is chosen in the numerical analysis for fast calculation. This method discretizes the integral into a matrix equation. This discretization can be considered as dividing the surface of antenna into small mesh [4]. To realize this method, we use computer simulation technology (CST) version 2016 from corporate company CST STUDIO SUITE [11]. The numerical simulation of the triangular truncated array antenna are shown in Section 3, especially at the resonant frequency, $f=5.2 \mathrm{GHz}$ where this antenna as basic configuration embedded on aircraft for the application of CP-SAR sensor both $T x$ and Rx. Each antenna can generate wave that yields a CP. The technique to achieve $\mathrm{CP}$ can be easily obtained i.e. by proper adjusting of the parameters, determining locus feed, and constructing feed [3, 12, 13].

Table 1. Technical specification of aircraft system

\begin{tabular}{lll}
\hline No & Antenna Parameters & Specification for aircraft \\
\hline 1. & Resonant Frequency $($ Center $)(\mathrm{GHz})$ & $C$-band: $5.0-5.5 \mathrm{GHz}$ \\
2. & Pulse Band Wide $(\mathrm{MHz})$ & $10-233.31$ \\
3. & Axial Ratio $(\mathrm{dB})$ & $\leq 3$ \\
4. & Antenna Efficiency $(\%)$ & $>80$ \\
5. & Gain Antenna $(\mathrm{dBic})$ & $10-36.6$ \\
6. & Azimuth Beamwidth $\left(^{\circ}\right)$ & $\geq 1.08$ \\
7. & Elevation Beamwidth $\left(^{\circ}\right)$ & $\geq 2.16$ \\
8. & Antenna Size $(\mathrm{m})$ & $2 \times 1$ \\
9. & Polarization $(T x / R x)$ & $\mathrm{RHCP}+$ LHCP \\
\hline
\end{tabular}

Figure 1 show the construction of the LHCP array two patches stack triangular truncated microstrip antenna consisting of two radiating patches fed by corporate feed microstrip-line with identical path lengths from input port to output ports and their parameters. The aim of the corporate feed microstrip-line design is to obtain a tapered and in-phase output current distribution [10, 14]. The parameter sizes of each radiating patch (patch 1 and patch 2) are the same, namely the length of triangular side, ar=17.7235 mm and $p r=20.72 \mathrm{~mm}$, the length of perturbation segment, $h r=4 \mathrm{~mm}$ and $t r=1.0034 \mathrm{~mm}$. Furthermore, the corporate feed microstrip-line has one node of $\mathrm{T}$-junction. This node has a function to distribute the current with the power of around $30 \mathrm{dBm}$ and to reach $2 \times 1$ patches having the same length from input port to radiating patches about $1.721 \lambda$ or $99.3035 \mathrm{~mm}$. In the upper layer of the top substrate, a triangular parasitic patch is placed at the center of the radiating patch in order to improve the axial ratio bandwidth (ARBW) and gain, with the length of triangular side, $a p=18.1093 \mathrm{~mm}$ and $p p=19.38 \mathrm{~mm}$, the length of perturbation 
segment, $h p=2.76 \mathrm{~mm}$ and $t p=1.5008 \mathrm{~mm}$. To reduce the undesired electromagnetic field emitted by the feeding, the upper layer of the top substrate is covered by copper and circle slot. The dimension of circle slot with $r s=15.7 \mathrm{~mm}$ has not significantly aff ected the axial ratio $(A r)$ performance, but in turn, it has changed the return loss (RL) characteristic of the antenna. The impedance bandwidth (IBW) and ARBW are also not aff ected by changing the circular slot diameter. Also, the circle slot does not aff ect significantly either the resonant frequency response or the surface current distribution direction of the parasitic patch [15, 16]. Moreover, the ground plane is a copper sheet placed at the bottom layer of the antenna with the size of $g 1=60 \mathrm{~mm}$ and $g 2=65 \mathrm{~mm}$.

To design the LHCP array two patches stack triangular truncated microstrip antenna, we choose a dielectric constant that corresponds to the appropriate thickness and loss tangent. A low value of dielectric constant increases the fringing field at the patch periphery. Also, a thicker substrate increases radiation power, reduces conductor loss, and improves impedance bandwidth. A high loss tangent rises dielectric loss and then reduces antenna efficiency [17-19]. In this paper, Nippon Pillar Packing (NPC) H220A is chosen as the antenna substrate. It has a conventional substrate with dielectric constant $\left(\varepsilon_{r}\right)$, and loss tangent $(\delta)$ are 2.17 and 0.0005 , respectively. Moreover, the total substrate thickness of LHCP antenna is $3.2 \mathrm{~mm}$.

To investigate the low power of the LHCP array two patches stack triangular truncated microstrip antenna, the antenna is constructed the mold of substantial planar array using microstrip-line that is fed directly to radiating patches and impacts on parasitic patches to yield the CP with wider bandwidth than other antennas operated in LP [20-22] and CP [23, 24]. It is because the right pattern of basic construction determines the superiority of array antenna design using patches stack and corporate feed microstrip-line [13, 25]. Although the corporate feeding-line design has been developed [2, 3, 7], the design was for the antenna bandwidth (IBW and ARBW) smaller than this novel antenna. Here, the design of LHCP two patches array antenna fed by corporate feed microstrip-line having low power and the antenna view on the $37^{\circ}$ angle side for CP-SAR application are discussed.

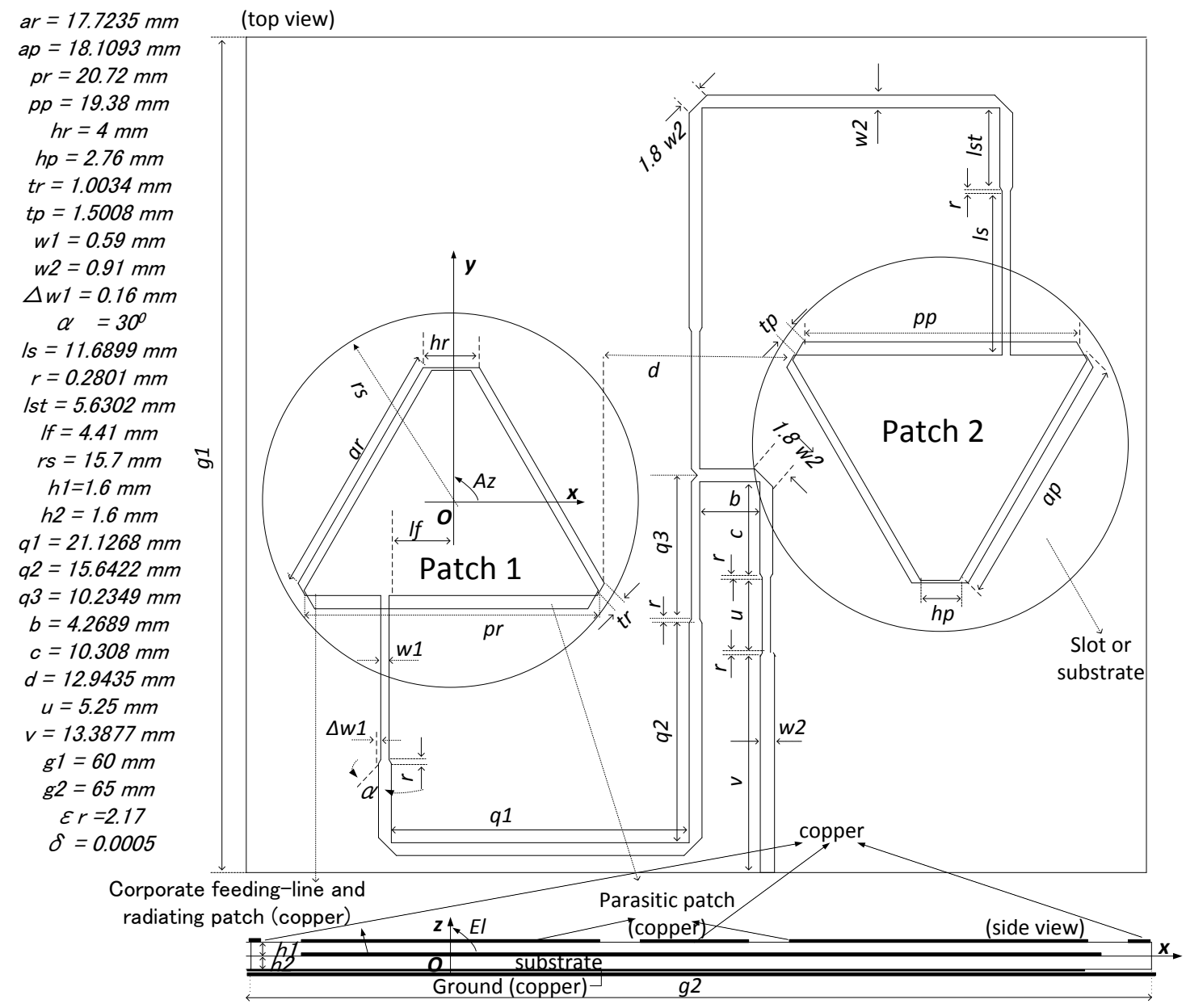

Figure 1. The construction of array two patches stack antenna 


\section{RESULTS AND DISCUSSION}

Figure 2 shows that the values of gain and axial ratio (Ar) for simulation of the LHCP array two patches stack triangular truncated microstrip antenna in the direction of $\theta=-37^{\circ}$ at the resonant frequency, $f=5.2 \mathrm{GHz}$, are about $7.24 \mathrm{dBic}$ and $1.99 \mathrm{~dB}$, respectively. In addition, the $3 \mathrm{~dB}-\mathrm{Ar}$ bandwidth is roughly equal $50 \mathrm{MHz}(0.96 \%)$. Figure 3 shows the relationship between the reflection coefficient $\left(S_{11}\right)$ and the frequency for the simulation $T x / R x$ array two patches stack triangular truncated microstrip antenna. Moreover, the value of $S_{11}$ at the resonant frequency is $-11.43 \mathrm{~dB}$. While the $S_{11}$ bandwidth is around $560 \mathrm{MHz}(10.77 \%)$. Figure 4 depicts the input impedance characteristic of the LHCP array two patches stack triangular truncated microstrip antenna for the real part and the reactance part of simulation at the resonant frequency that are successively $50.67 \Omega$ and $-1.67 \Omega$. These results are relative close to $50 \Omega$ and $0 \Omega$, so the reactance looks capasitive. In the feed network, the length from input port to output ports must be fixed at $l \times \lambda / 4(l=1,3,5$, etc. $)$ to achieve the optimal current intensity [2, 14]. In this work, we use $l=7$ or the distance between input port to output ports is $99.3035 \mathrm{~mm}$.

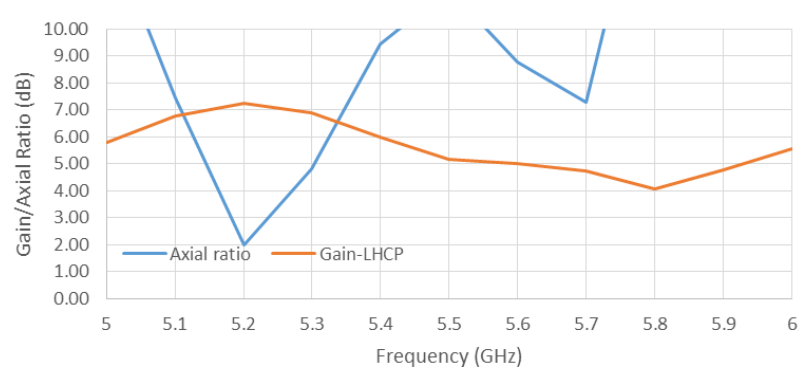

Figure 2. Frequency characteristic of array two patches stack antenna

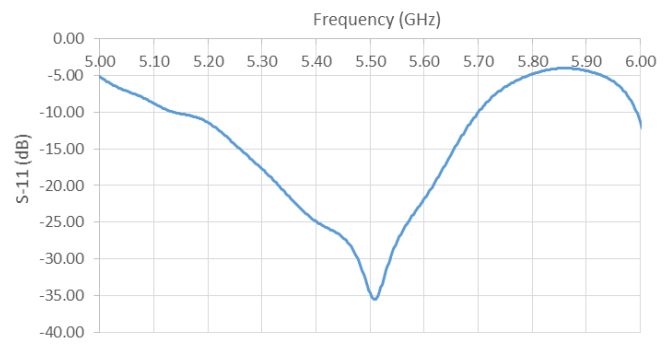

Figure 3. $S$-parameter of array two patches stack antenna

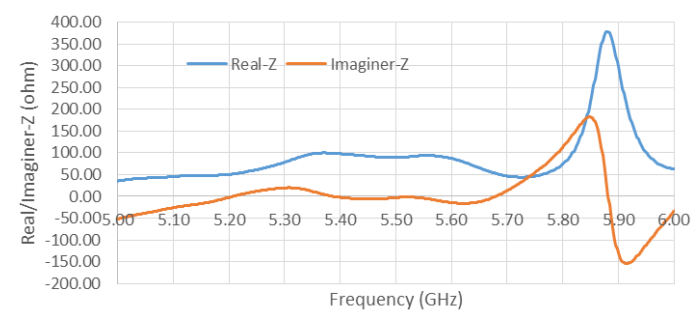

Figure 4. Input impedance of array two patches stack antenna

Figure 5 and Figure 6 depict the relationship between gain and elevation or $\theta$-angle produced from the LHCP array two patches stack triangular truncated microstrip antenna as azimuth $(A z)$ direction (positive- $\theta$ for $A z=0^{\circ}$ or $90^{\circ}$ and negative- $\theta$ for $A z=180^{\circ}$ or $270^{\circ}$ ) of CP-SAR at $f=5.2 \mathrm{GHz}$. At the elevation $-37^{\circ}$, the average values of maximum gain and $A r$ of this antenna are about $7.24 \mathrm{dBic}$ and $1.99 \mathrm{~dB}$, respectively. Furthermore, the values of $3 \mathrm{~dB}-A r$ beamwidth are $35^{\circ}$ from $-50^{\circ}$ to $-15^{\circ}\left(A z=180^{\circ}\right.$ or negative- $\theta$ ) and around $68^{\circ}$ from $27^{\circ}$ to $95^{\circ}\left(A z=0^{\circ}\right.$ or positive- $\theta$ ). Moreover, $3 \mathrm{~dB}-A r$ beamwidth for $A z=270^{\circ}$ or negative $-\theta$ is $40^{\circ}$ from $-55^{\circ}$ to $-15^{\circ}$, while for $A z=90^{\circ}$ or positive $-\theta$, the value is around $69^{\circ}$ from $26^{\circ}$ to $95^{\circ}$. All of these values satisfy the targeted elevation beamwidth of $\geq 2.16^{\circ}$ at Table 1 for better resolution of CP-SAR. 


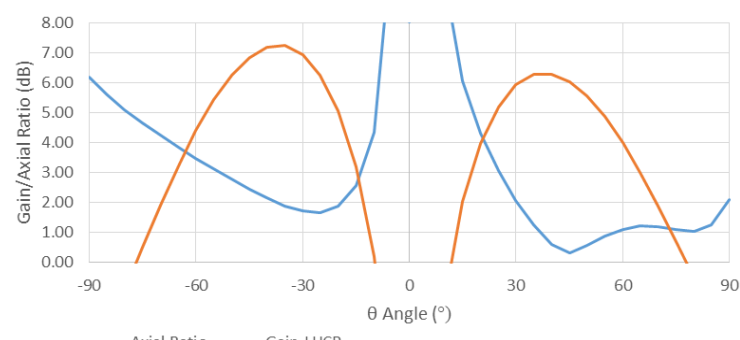

Figure 5. Radiation pattern of array two patches stack antenna on $x$ - $z$ plane, $f=5.2 \mathrm{GHz}, \phi=0^{\circ}$

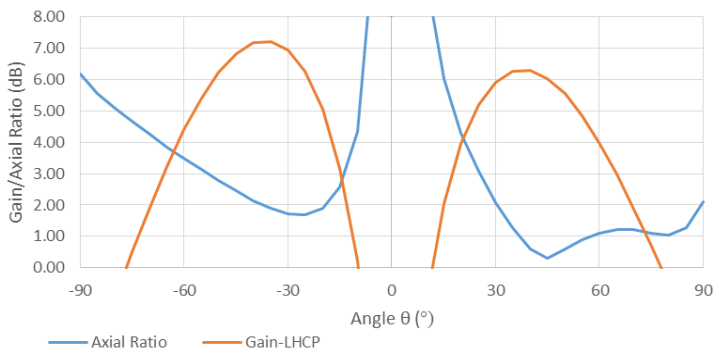

Figure 6. Radiation pattern of array two patches stack antenna on $y-z$ plane, $f=5.2 \mathrm{GHz}, \phi=90^{\circ}$

Figure 7 and Figure 8 describe the azimuth plane in the area of $\theta=-37^{\circ}$ for LHCP at frequency 5.2 GHz. The values of maximum gain and minimum $A r$ on this plane are $7.253 \mathrm{dBic}$ on $\phi=5^{\circ}$ and $1.002 \mathrm{~dB}$ on $\phi=215^{\circ}$. The major values of $3 \mathrm{~dB}-A r$ beamwidth on $x-y$ plane, $\phi=0^{\circ}$ are about $125^{\circ}$ from $\phi=305^{\circ}$ to $\phi=70^{\circ}$ and around $80^{\circ}$ from $\phi=153^{\circ}$ to $\phi=233^{\circ}$. While for the $x-y$ plane, $\phi=90^{\circ}$ are roughly $125^{\circ}$ from $\phi=35^{\circ}$ to $\phi=160^{\circ}$ and approximately $83^{\circ}$ from $\phi=240^{\circ}$ to $\phi=323^{\circ}$. These results exhibit that the targeted azimuth beamwidth $\geq 1.08^{\circ}$ can occur for the resolution of CP-SAR aircraft. Figure 9 shows the antenna efficiency about $90.13 \%$ for the LHCP array two patches stack triangular truncated microstrip antenna on a target frequency of $5.2 \mathrm{GHz}$. This result obtain the resolution of CP-SAR of the targeted antenna efficiency of $80 \%$.

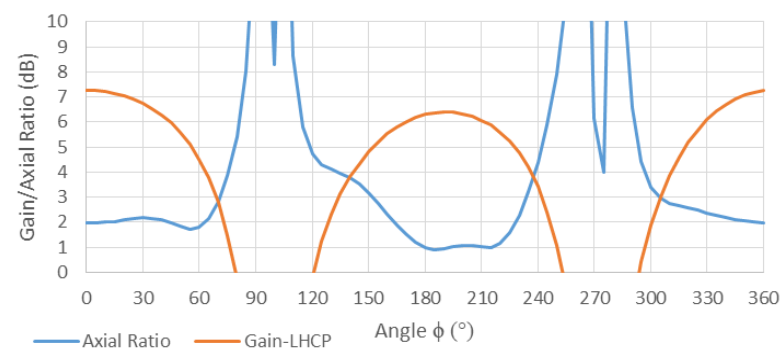

Figure 7. Radiation pattern on $x-y$ plane of array two patches stack antenna, $f=5.2 \mathrm{GHz}, \theta=-37^{\circ}, \phi=0^{\circ}$

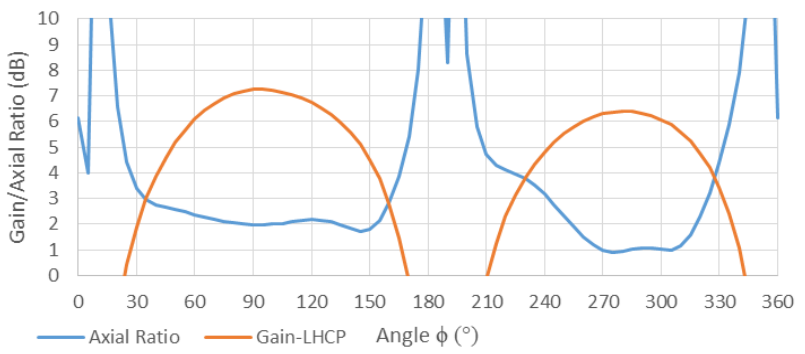

Figure 8. Radiation pattern of array two patches stack antenna on $x-y$ plane, $f=5.2 \mathrm{GHz}, \theta=-37^{\circ}, \phi=90^{\circ}$ 


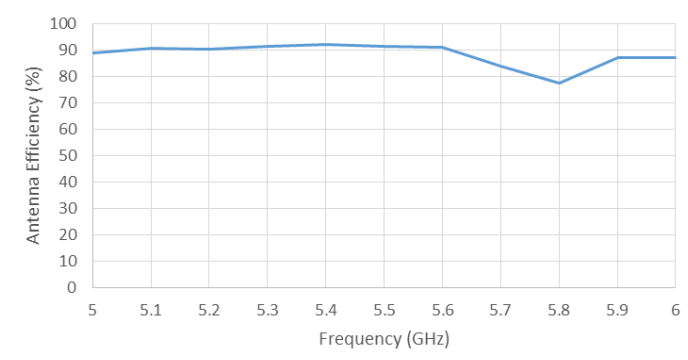

Figure 9. Antenna efficiency of array two patches stack antenna

\section{CONCLUSION}

In an effort to meet the basic configuration for CP-SAR that is affixed to the aircraft body with compact, small and simple, the LHCP array two patches stack triangular truncated microstrip antenna has been studied. Performance results, such as characteristic frequencies, $S$-parameters, input impedances, radiation patterns, and efficiency are as follows: (i) The gain and axial ratio (Ar) values for this antenna simulation in the direction $\theta=-37^{\circ}$ at resonant frequency of $5.2 \mathrm{GHz}$, were respectively around $7.24 \mathrm{dBic}$ and $1.99 \mathrm{~dB}$.(ii) $3 \mathrm{~dB}-A r$ bandwidth of $50 \mathrm{MHz}(0.96 \%)$ was relatively wider than working on the $L$-band frequency. (iii) The value of $S_{11}$ at the resonant frequency was $-11.43 \mathrm{~dB}$ and its bandwidth value was around $560 \mathrm{MHz}(10.77 \%)$. (iv) Input impedance of the real part of this antenna from simulation at resonance frequency, $f=5.2 \mathrm{GHz}$ was $50.67 \Omega$ relatively close to $50 \Omega$. While the reactance portion of this antenna was $-1.67 \Omega$, it looked capacitive and approached $0 \Omega$. (v) The maximum gain and the minimum $A r$ values of this antenna in the gain/axial ratio function to the elevation angle or $\theta$-angle were around 7,243 $\mathrm{dBic}$ and $1,985 \mathrm{~dB}$ at $\theta=-37^{\circ}$ and around $6.3 \mathrm{dBic}$ and $0,979 \mathrm{~dB}$ at $\theta=37^{\circ}$. (vi) The maximum gain and minimum $A r$ values in the relation function of gain/axial ratio to azimuth angle or $\phi$-angle were about $7.253 \mathrm{dBic}$ at $\phi=5^{\circ}$ and $1.002 \mathrm{~dB}$ at $\phi=215^{\circ}$. (vii) The antenna efficiency value of this antenna was around $90.13 \%$ at a target frequency of $5.2 \mathrm{GHz}$ which has exceeded the target set by more than $80 \%$.

\section{ACKNOWLEDGEMENTS}

The authors would like to express their gratitude to the Microelectronic Research Laboratory (MeRL), Electrical Engineering and Computer Science, Graduate School of Natural Science and Technology, Kanazawa University, Japan for the support of facilities to collect the data in this research. Also, special thanks to Power System Engineering and Energy Management Research Group (PSeeMRG), Department of Electrical Engineering, Faculty of Engineering, Brawijaya University for the support in my research and publication.

\section{REFERENCES}

[1] M. F. E. Purnomo and A. Kitagawa, "Development of Equilateral Triangular Array Antenna with Truncated-Tip for Circularly Polarized-Synthetic Aperture Radar Sensor Application,"Proceedings of 12th European Conference on Synthetic Aperture Radar, Aachen, pp. 1-6, 2018.

[2] Yohandri, et al., "Development of Circularly Polarized Array Antenna for Synthetic Aperture Radar Sensor Installed on UAV," Progress In Electromagnetics Research C., vol. 19, pp. 119-133, 2011.

[3] M. Baharuddin, et al., "Equilateral Microstrip Antenna for Circularly-Polarized Synthetic Aperture Radar," Progress In Electromagnetics Research C., vol. 8, pp. 107-120, 2009.

[4] J. T. S. Sumantyo, K. Ito and M. Takahashi, "Dual-Band Circularly Polarized Equilateral Triangular-Patch Array Antenna for Mobile Satellite Communications,"IEEE Transactions on Antennas and Propagation, vol. 53, no. 11, pp. 3477-3485, 2005.

[5] Biao Du and E.K. Ning Yung, "A Single-Feed $\mathrm{TM}_{21}$ Mode Circular Patch Antenna with Circular Polarization," Microwave and Optical Technology Letters, vol. 33, pp. 154-155, 2002.

[6] M.F.E. Purnomo and A. Kitagawa, "Analysis Performance of Triangle Microstrip Antenna for Basic Construction of Circularly Polarized-Synthetic Aperture Radar Application," Jurnal Teknologi, vol. 80, no. 2, pp. 94-104. 2018.

[7] M. F. E. Purnomo and A. Kitagawa, "Triangular Microstrip Antenna for Circularly-Polarized Synthetic Aperture Radar Sensor Application," Indonesian Journal of Electrical Engineering and Computer Science, vol. 12, no. 1, pp. 310-318, 2018.

[8] J. M. Parenreng and A. Kitagawa, "Resource Optimization Techniques and Security Levels for Wireless Sensor Networks Based on the ARSy Framework," Sensors, vol. 18, no. 1594, pp. 1-15, 2018.

[9] P. D. Prasetyo Adi and A. Kitagawa, "ZigBee Radio Frequency (RF) Performance on Raspberry Pi 3 for Internet of Things (IoT) Based Blood Pressure Sensors Monitoring," International Journal of Advanced Computer Science and Applications, vol. 10, no. 5, pp. 18-27, 2019.

[10] K. C. Gupta, et al., "Microstrip Lines and Slotlines," Second Edition, Artech House: Massachusetts, UK, 1996. 
[11] CST STUDIO SUITE 2016, "Microwave - Radio Frequency - Optical," 2016.

[12] Edwar and A. Munir, "Development of SAR Transmitter for Nanosatellite-Based Remote Sensing Application," The 5th International Conference on Electrical Engineering and Informatics, 2015.

[13] Chia-Luan Tang, Jui-Han Lu and Kin-Lu Wong, "Circularly Polarised Equilateral-Triangular Microstrip Antenna with Truncated Tip," Electronics Letters, vol. 34, no. 13, pp. 1277-1278, 1998.

[14] T. S. Horng and N. G. Alexopoulos, "Corporate Feed Design for Microstrip Arrays. IEEE Transactions on Antennas and Propagation, vol. 41, no. 12, pp. 1615-1624, 1993.

[15] C. E. Santosa, et al., "Development of a Low Profile Wide-Bandwidth Circularly Polarized Microstrip Antenna for C-Band Airborne CP-SAR Sensor," Progress In Electromagnetics Research, vol. 81, pp. 77-88, 2018.

[16] C. E. Santosa, et al., "Subarray Design for $C$-Band Circularly-Polarized Synthetic Aperture Radar Antenna Onboard Airborne," Progress In Electromagnetics Research, vol. 163, pp. 107-117, 2018.

[17] A. A. Kishk and L. Shafai, "The Effect of Various Parameters of Circular Microstrip Antennas on Their Radiation Efficiency and The Mode Excitation," IEEE Transactions on Antennas and Propagation, vol. 34, no. 8, pp. 969-976, 1986.

[18] S. Salihah, et al., "A MIMO H-Shape Dielectric Resonator Antenna for 4G Applications," Indonesian Journal of Electrical Engineering and Computer Science, vol. 10 no. 2, pp. 648-653, 2018.

[19] N. H. Shahadan, et al., "Higher-order Mode Rectangular Dielectric Resonator Antenna for 5G Applications," Indonesian Journal of Electrical Engineering and Computer Science, vol. 5, no. 3, pp. 584-592, 2017.

[20] Y. K. Chan and V. C. Koo, "The Design and Development of Unmanned Aerial Vehicle Synthetic Aperture Radar," Progress In Electromagnetics Research Online, vol. 7, no. 7, pp. 685-688, 2011.

[21] V. C. Koo, et al., "A New Unmanned Aerial Vehicle Synthetic Aperture Radar for Environmental Monitoring," Progress In Electromagnetics Research, vol. 122, pp. 245-268, 2012.

[22] A. Aguasca, R. Acevo-Herrera, A. Broquetas, J. J. Mallorqui and X. Fabregas, "ARBRES: Light-Weight CW/FM SAR Sensors for Small UAVs," Sensors, vol. 13, no. 3, pp. 3204-3216, 2013.

[23] M. F. E. Purnomo, et al., "The Four Patches of Triangular Microstrip Antennas as Configuration of CP-SAR," Proceedings of 2019 2nd International Conference on Electronics and Electrical Engineering Technology (EEET 2019), Penang, pp. 55-61, 2019.

[24] M. F. E. Purnomo, et al., "Development of Triangular Array Eight Patches Antennas for Circularly-Polarized Synthetic Aperture Radar Sensor," Telecommunication, Computing, Electronics and Control, vol. 18, no. 2, pp. 631-639, 2020.

[25] J. T. Sri Sumantyo, et al., "Development of Circularly Polarized Synthetic Aperture Radar on-Board Microsatellite," PIERS Proceedings, Beijing, pp. 382-385, 2009

\section{BIOGRAPHIES OF AUTHORS}

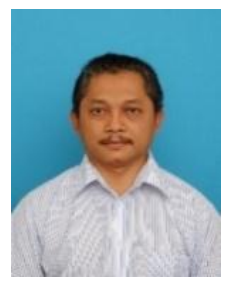

Muhammad Fauzan Edy Purnomo was born in Banjarmasin, Indonesia, in June 1971. He received the bachelor engineering (B.E.) and master engineering (M.E.) degrees in electrical engineering from University of Indonesia, Jakarta, Indonesia in 1997 and 2000, respectively. He has graduated the doctoral degree in electrical engineering and computer science from Kanazawa University, Kanazawa, Japan on September 2018. Now, he is a visiting scholar at Microelectronic Research Laboratory (MeRL), Division of Electrical Engineering and Computer Science, Graduate School of Natural Science and Technology, Kanazawa University, Japan until March 2019. From 2000 until present, he is working as lecturer at the Electrical Department Brawijaya University, Malang, Indonesia. His main interests are in the areas of microwave antennas, radio frequency (RF) circuit, wave signal processing, array microstrip antennas, mobile cellular and satellite communications, remote sensing, synthetic aperture radar (SAR), and circularly-polarized synthetic aperture radar (CP-SAR).

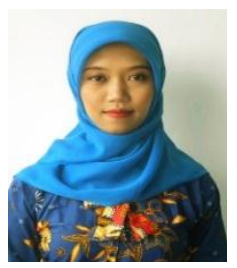

Vita Kusumasari was born in 1983 in Malang, Indonesia. She obtained the bachelor degree in Mathematics in 2005 and the master degree in Mathematics Education in 2010 from Universitas Negeri Malang, Indonesia. She received the Ph.D degree in mathematical and physical sciences in 2017 from Kanazawa University, Japan. Currently, she is a lecturer in Mathematics Department, Universitas Negeri Malang. Her interests are numerical analysis and differential equations.

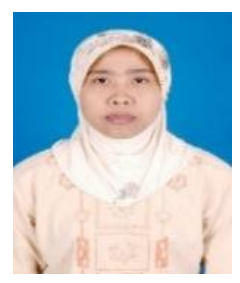

Rusmi Ambarwati was born in 1972 in Nganjuk, Indonesia. She received the bachelor engineering (B.E) and master engineering degrees in electrical engineering from Sepuluh Nopember Institute of Technologi, Indonesia in 1997 and 2001. Currently, she is a lecturer in Electrical Engineering Department, Brawijaya University. Her research interests include wireless communication and networks, and signal processing. 

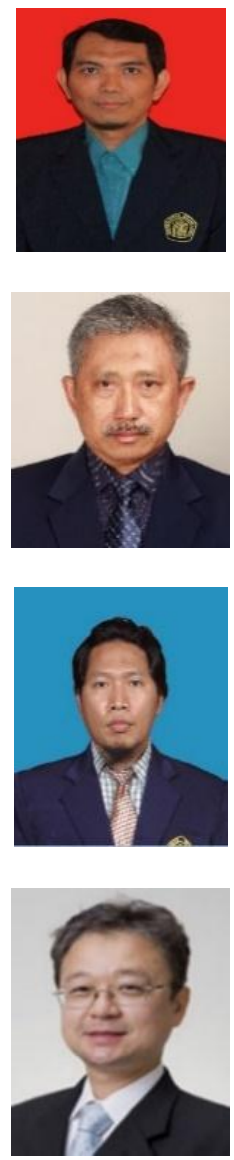

Sigit Kusmaryanto was born in 1970 in Madiun, Indonesia. He received the bachelor engineering (B.E) in electrical enginering from Brawijaya University and master engineering degrees in electrical engineering from Gadjah Mada University, Indonesia in 1993 and 2011. Currently, she is a lecturer in Electrical Engineering Department, Brawijaya University. Her research interests include wireless communication and networks, and signal processing.

Sholeh Hadi Pramono was borned in 1958. He obtained his bachelor degree in 1985 majoring in electrical power system from Universitas Brawijaya. In 1990 and $2009 \mathrm{He}$ obtained his Master and doctoral degree repectively from Universitas Indonesia majoring in optoelectrotechniques and laser application. His major research is in optical communication, photovoltaic, optoelectronics and artificial intelligence. He has been a lecturer in Universitas Brawijaya since 1986.

Dwi Fadila Kurniawan was born in 1972 in Jakarta, Indonesia. He received the bachelor engineering (B.E) from Brawijaya University, Indonesia in 1997 and master engineering degrees in electrical engineering from Sepuluh Nopember Institute of Technologi, Indonesia in 2001. Currently, he is a lecturer in electrical engineering department, Brawijaya University. His research interests include wireless communication, artificial intelligent, networks and antenna.

Akio Kitagawa was born in Hikone, Japan in 1961. He received the B.E., the M.E., and the Ph.D degree from Nagoya Institute of Technology, Nagoya, Japan in 1985, 1987 and 1991, respectively. Since 1989, He worked for the Department of Electrical and Computer Engineering, Kanazawa University, Japan. From 2001 to 2003, He was with the Department of Information and Systems Engineering, Kanazawa University, Japan. From 2004 to 2007, He had been with Division of Electrical Engineering and Computer Science, Graduate School of Natural Science and Technology, Kanazawa University. Since 2008, He is working with College of Science and Engineering, School of Electrical, Information and Communication Engineering in Kanazawa University. His research interests include a phase change nonvolatile RAM, VLSI design automation, integrated sensor systems, RF circuit design and VLSI applications to mobile systems. 